Article

\title{
Comparison of Sample Preparation Methods for Multielements Analysis of Olive Oil by ICP-MS
}

\author{
Fadwa Damak ${ }^{1,2, *}$, Maki Asano ${ }^{3}$, Koji Baba ${ }^{2}$, Mohamed Ksibi ${ }^{4}$ and Kenji Tamura ${ }^{3}$ \\ 1 Tsukuba Life Science Innovation (T-LSI) Program, School of Integrative and Global Majors, University of \\ Tsukuba, 1-1-1 Tennodai, Ibaraki 305-8577, Japan \\ 2 Institute of Agro-Environmental Sciences, NARO, 3-1-3 Kannondai Tsukuba, Ibaraki 305-0856, Japan \\ 3 Faculty of Life and Environmental Sciences, University of Tsukuba, Ibaraki 305-8572, Japan \\ 4 Environmental Engineering and Ecotechnology Laboratory (LGEET), National School of Engineers of \\ Sfax (ENIS), University of Sfax, Route de Soukra Km 4 P.O. Box 1173, Sfax 3038, Tunisia \\ * Correspondence: f.damak@yahoo.fr
}

Received: 30 June 2019; Accepted: 15 August 2019; Published: 19 August 2019

\begin{abstract}
Elemental analysis of olive oils by Inductively Coupled Plasma Mass Spectrometry (ICP-MS) is challenging because of the high organic load in olive oil samples and the low analyte concentrations. However, conflicting operating procedures in the preparation of oils prior to analysis by ICP-MS have been reported to overcome these difficulties. This study compared three methods of inorganic elements' extraction from olive oils: The two commonly used microwave-assisted, acid digestion, and liquid-liquid, ultrasound-assisted extraction methods; and an optimized method: The combined microwave digestion-evaporation. Overall, microwave digestion-based methods did not compare opportunely, and ultrasound-assisted extraction was found to provide the best accord between simplicity of use, detection limits and precision improvement. The detection limits were in the range of $0.3-160 \mu \mathrm{g} \cdot \mathrm{kg}^{-1}, 0.012-190 \mu \mathrm{g} \cdot \mathrm{kg}^{-1}$ and $0.00061-1.5 \mu \mathrm{g} \cdot \mathrm{kg}^{-1}$, while repeatabilities were in the range of $5-21 \%, 5.4-99 \%$ and $5.1-40 \%$ for the microwave digestion, the combined digestion-evaporation and the ultrasound assisted extraction, respectively. The ultrasound-assisted extraction is therefore recommended as a preparation method for olive oils prior to analysis by ICP-MS. The broader range of elements that can be accurately detected is expected to help increase the discriminatory power and performance of geographical traceability models.
\end{abstract}

Keywords: multielements; olive oil; ICP-MS; microwave digestion; evaporation; ultrasound-assisted extraction

\section{Introduction}

Determination of multielements in olive oils has gained an important place in the scientific community because of their increased application in geographical traceability studies. In fact, by detecting more elements, the probability of including elements with higher discriminatory power increases, improving the performance of the classification models [1]. But the extraction of metals from edible oils and elements' determination by ICP-MS is difficult, and one of the most challenging analytical problems, due to the high viscosity of the matrix, leading to problems in leaching and dissolving [2]. Additionally, the edible oil matrix is characterized by: (i) A high organic load that increases the matrix effects and the possibility of polyatomic molecular interferences from elements like C, N and S. This high organic content can result in carbon deposition on the sampling cone and the loss of sensitivity, and (ii) an extremely low concentration of elements that makes it extremely prone to contamination during preparation [3]. To overcome these difficulties, different sample preparation procedures were proposed and applied and were thoroughly reviewed elsewhere [4]. A thorough compilation of the literature on multielement determinations in edible oils revealed that the microwave 
digestion with $\mathrm{HNO}_{3}$ and sometimes with addition of $\mathrm{H}_{2} \mathrm{O}_{2}$ is the most widely proposed, validated and used preparation method [5-11].

However, after reviewing in our last study, the results of metals concentrations in olive oils from studies published in the last decade, we reported for the first time in the literature a wide variability in these concentrations, even within the same country. We presumed that such variability could have been at least partially affected by the use of different and conflicting preparation methods [12]. This same observation was confirmed in another recently published study that also pointed out the limitations of the microwave digestion method. In fact, out of the initially analyzed twenty-nine elements, the authors could only detect seven elements. A high detection limit was amongst the most problematic factors leading to the elimination of almost three quarters of the elements of interest [13]. In fact, in the microwave-assisted digestion, up to $9 \mathrm{~mL}$ and $2 \mathrm{~mL}$ of concentrated $\mathrm{HNO}_{3}$ and $\mathrm{H}_{2} \mathrm{O}_{2}$, respectively, are used to ensure total decomposition of the sample. The direct implications of the use of this considerable amount of concentrated acid are: (i) The corrosive nature of the digests to the ICP-MS components [14], and (ii) the high viscosity of the analytical solutions, which may result in matrix effects. The approach usually used to counter these effects is to make further dilutions (up to 250 folds dilution) to ensure a maximal residual acidity of $1 \%$ to $5 \%$ which is the usual acid medium of choice for most ICP-MS analyses [15]. While the actual concentration of some elements (e.g., Na, $\mathrm{K}, \mathrm{Mg}, \mathrm{Ca}, \mathrm{Fe}$ and $\mathrm{Zn}$ ) can reach the ppm level, that of other trace elements can be as low as the ppt level [16]. The further dilution of these extremely low concentrations would result in going below ICP-MS detection capabilities.

This situation highlights the need for a unique standardized preparation method in order to ensure consistency and allow rigorous comparisons between oils from different origins. This specific procedure also needs to improve the method's detection limits, so more elements can be detected and then used as independent variables in the traceability model.

The first solution one can think about is to make sure to obtain lower residual acidity so that we reduce the volume of ultrapure water required to dilute the samples. This is possible by: (i) Dispelling the excess of the residual acid in the digest by evaporation to near dryness or (ii) decreasing the initially used amount of concentrated nitric acid. The latter possibility implies that the complete decomposition of the organic matrix may not be possible, so another type of method instead of the microwave-assisted digestion should be used: It is the liquid-liquid ultrasound-assisted extraction. This strategy has the benefit of speed and simplicity of application. It can also reduce the amount of reagents through the use of dilute acid solutions. Amelioration of the analytes' recoveries in liquid-liquid extraction can be obtained through the use of ultrasonic energy [17].

The main objective of this study is to compare three methods of olive oil samples preparation prior to ICP-MS analysis: The two current microwave-assisted digestion, and ultrasound-assisted extraction of multielements methods and an optimized combined microwave digestion-evaporation method. These three methods are described in detail and their results compared to aid choosing the method that reaches lower detection limits and higher precision. The ultimate goal is to recognize the most robust preparation method which allows the reliable quantification by ICP-MS of multielements in olive oil samples.

The International Olive Council, whose mission is to develop and standardize chemical olive oil testing methods, has not yet specified a standard multielement determination method, contrary to other compounds (fatty acids, triacylglycerols, aliphatic alcohols, etc.), despite the proven importance of multielements in traceability issues. This has lead to the conflicting and wide variability of the reported results of multielements concentrations in olive oils presumably caused by using different preparation methods. The outcome of this study can then help researchers and analysts choose the best method, which is the ultrasound-assisted extraction for olive oil preparation for traceability purpose, to ensure consistency. 


\section{Materials and Methods}

\subsection{Equipment}

A microwave oven equipped with a 10 position rotor and capable of delivering $1600 \mathrm{~W}$ of power (ETHOS 1600, Advanced Microwave Labstation, Milestone Inc., Sorisole, Italy) was used for closed-vessel digestion of samples and method blanks. Capped Teflon tubes were used to decompose samples and also evaporate them when necessary.

An ultrasonic bath capable of delivering $300 \mathrm{~W}$ of power and $55^{\circ} \mathrm{C}$ of maximal temperature was used to carry out the liquid-liquid extraction of elements.

A commercial hotplate placed inside a fume hood was used to evaporate the residual acid to near dryness after digestion. The residual digests were kept in their initial recipients that were protected from the laboratory environment and potential air-borne contamination by a cone made by rolling a laboratory clean-tissue.

DigiTUBES that have an ultra-low leachable metal content, of class A tolerance at the $25 \mathrm{~mL}$ graduation (SCP Science, Montréal, QC, Canada), were used to collect samples after microwave digestion and dilute them to volume with ultrapure water.

A Milli-Q Integral 3 (Nihon Millipore, Tokyo, Japan) was used to prepare ultrapure water that was used to prepare all solutions, make dilutions and rinse material at all times during the experiment.

The quantification of the elements was carried out with ICP-MS (Elan DRC-e (Perkin-Elmer SCIEX, Concord, ON, Canada) and NexION 300XX (Perkin-Elmer, Waltham, MA, USA)). Samples were introduced by means of a borosilicate glass nebulizer. ICP-MS is known to suffer from unwanted polyatomic isobaric interferences. Therefore, the elements were monitored in standard, kinetic energy discrimination (KED: He collision) and dynamic reaction cell (DRC: $\mathrm{CH}_{4}$ reaction) modes to check for and reduce polyatomic interferences, and the appropriate isotopes were used. Instrument performance was checked by a midrange continuing calibration verification $\left(5 \mu \mathrm{g} \cdot \mathrm{L}^{-1}\right)$ every ten samples. Indium was used as an internal standard in all the three methods and added to all samples, calibration solutions, method blanks and solutions prepared for quality control to yield a concentration of $1 \mu \mathrm{g} \cdot \mathrm{L}^{-1}$.

The operating conditions and parameters of ICP-MS are shown in Table 1 for each method.

Table 1. ICP-MS operating conditions.

\begin{tabular}{|c|c|c|c|}
\hline \multirow{2}{*}{ Parameter } & \multicolumn{3}{|c|}{ Method } \\
\hline & Microwave Digestion & Digestion-Evaporation & Ultrasonic Extraction \\
\hline Instrument & ELAN & NexION & NexION \\
\hline ICP Rf power $(W)$ & 1100 & 1600 & 1600 \\
\hline Plasma Ar flow rate $\left(\mathrm{L} \cdot \mathrm{min}^{-1}\right)$ & 15 & 18 & 18 \\
\hline Auxiliary Ar flow rate $\left(\mathrm{L} \cdot \mathrm{min}^{-1}\right)$ & 1.30 & 1.20 & 1.20 \\
\hline $\begin{array}{c}\text { Nebulizer (carrier gas) flow rate } \\
\left(\mathrm{L} \cdot \mathrm{min}^{-1}\right)\end{array}$ & 0.77 & 0.98 & 0.98 \\
\hline Sampler and skimmer cones & Nickel & Nickel & Nickel \\
\hline lens voltage (Deflector voltage) (V) & 7.5 & -11.50 & -11.50 \\
\hline Analog stage voltage $(\mathrm{V})$ & -1700 & -1800 & -1800 \\
\hline Pulse stage voltage $(\mathrm{V})$ & 950 & 1100 & 1100 \\
\hline Discriminator threshold (V) & 19 & 13 & 13 \\
\hline Quadrupole rod offset (V) & $\begin{array}{l}-1.5(\mathrm{STD}) \\
-7.5(\mathrm{DRC})\end{array}$ & $\begin{array}{c}0 \text { or } 0.50(\mathrm{STD}) \\
-12(\mathrm{KED}) \\
-7.5(\mathrm{DRC})\end{array}$ & $\begin{array}{c}0 \text { or } 0.50(\mathrm{STD}) \\
-12(\mathrm{KED}) \\
-7.5(\mathrm{DRC})\end{array}$ \\
\hline Detector & Pulse & Pulse & Pulse \\
\hline Speed of peristaltic pump (rpm) & 20 & 20 & 20 \\
\hline Sweeps/reading & 20 & 20 & 20 \\
\hline Replicate/reading & 1 & 1 & 1 \\
\hline Replicates & 3 & 3 & 3 \\
\hline Dwell time (ms) & 50 & 50 & 50 \\
\hline
\end{tabular}


Table 1. Cont.

\begin{tabular}{|c|c|c|c|}
\hline \multirow{2}{*}{ Parameter } & \multicolumn{3}{|c|}{ Method } \\
\hline & Microwave Digestion & Digestion-Evaporation & Ultrasonic Extraction \\
\hline Scan mode & Peak hopping & Peak hopping & Peak hopping \\
\hline $\begin{array}{l}\text { STD and KED: rejection parameter } \\
\quad \mathrm{a} \text { and rejection parameter } \mathrm{q}\end{array}$ & $0,0.25$ & $0,0.25$ & $0,0.25$ \\
\hline $\begin{array}{c}\text { DRC mode: } \mathrm{CH}_{4} \text { reaction gas flow } \\
\left(\mathrm{L} \cdot \mathrm{min}^{-1}\right)\end{array}$ & 0.60 & 0.60 & 0.60 \\
\hline $\begin{array}{l}\text { DRC mode: rejection parameter a } \\
\text { and Rejection parameter } \mathrm{q}\end{array}$ & $0,0.65$ & $0,0.65$ & $0,0.65$ \\
\hline $\begin{array}{l}\text { KED mode He reaction gas flow } \\
\qquad\left(\mathrm{L} \cdot \mathrm{min}^{-1}\right)\end{array}$ & - & 3.5 & 3.5 \\
\hline
\end{tabular}

STD, standard mode; DRC, dynamic reaction cell mode; KED, kinetic energy discrimination mode.

\subsection{Chemicals}

61\% electronic-grade (EL) nitric acid $\mathrm{HNO}_{3}$ (Kanto Chemicals, Tokyo, Japan), 30\% atomic absorption spectrometry-grade hydrogen peroxide $\mathrm{H}_{2} \mathrm{O}_{2}$ (Wako Pure Chemical Industries, Osaka, Japan) for ultra-trace analysis, and $35 \% \mathrm{HCl}$ (Wako Pure Chemical Industries, Osaka, Japan) were used to prepare samples. The influence of instrumental drift was corrected by using Indium (In) as internal standard prepared from $10 \mathrm{mg} \cdot \mathrm{L}^{-1}$ CLISS-1 (SPEX CertiPrep, Metuchen, NJ, USA) to yield a concentration of $1 \mu \mathrm{g} \cdot \mathrm{L}^{-1}$ in the samples, method blanks and calibration solutions.

\subsection{Description of the Methods}

\subsubsection{Microwave Digestion}

Mineralization of olive oil samples was carried out according to the method described by Llorent-Martinez, Fernandez-de Cordova, Ortega-Barrales, and Ruiz-Medina with minor modifications [18]. The method consists of weighing $0.5 \mathrm{~g}$ of vigorously shaken sample and placing it directly into the digestion vessel, and adding $7 \mathrm{~mL}$ of $\mathrm{HNO}_{3}$ and $1 \mathrm{~mL}$ of $\mathrm{H}_{2} \mathrm{O}_{2}$. The vessels were placed in the microwave digestion system. The program of the microwave consisted of a ramp of $15 \mathrm{~min}$ to reach $200{ }^{\circ} \mathrm{C}$ and $1000 \mathrm{~W}$, where the system was maintained for an additional $15 \mathrm{~min}$. After being cooled to room temperature, samples were transferred into DigiTUBES and diluted to volume with ultrapure water. Samples were filtered using a $0.20 \mu \mathrm{m}$ pore size syringe filter (Captiva econofilter, Agilent Technology, USA). Vessels were cleaned using the same microwave operating program after each digestion batch and successively rinsed with Milli-Q water.

\subsubsection{Optimization of the Combined Digestion-Evaporation}

\section{Description of the Protocol}

Three batches were designed with precise samples and reagents amounts specified and microwave digestion parameters defined according to the manufacturer's recommendations (Figure 1). The first step of this method's development was focused on optimizing the microwave working parameters (i.e., temperature $\left({ }^{\circ} \mathrm{C}\right)$, time and number of digestion steps), and digestion vessels were prepared in duplicate in each batch so that one can be used to test the evaporation effect later on. 

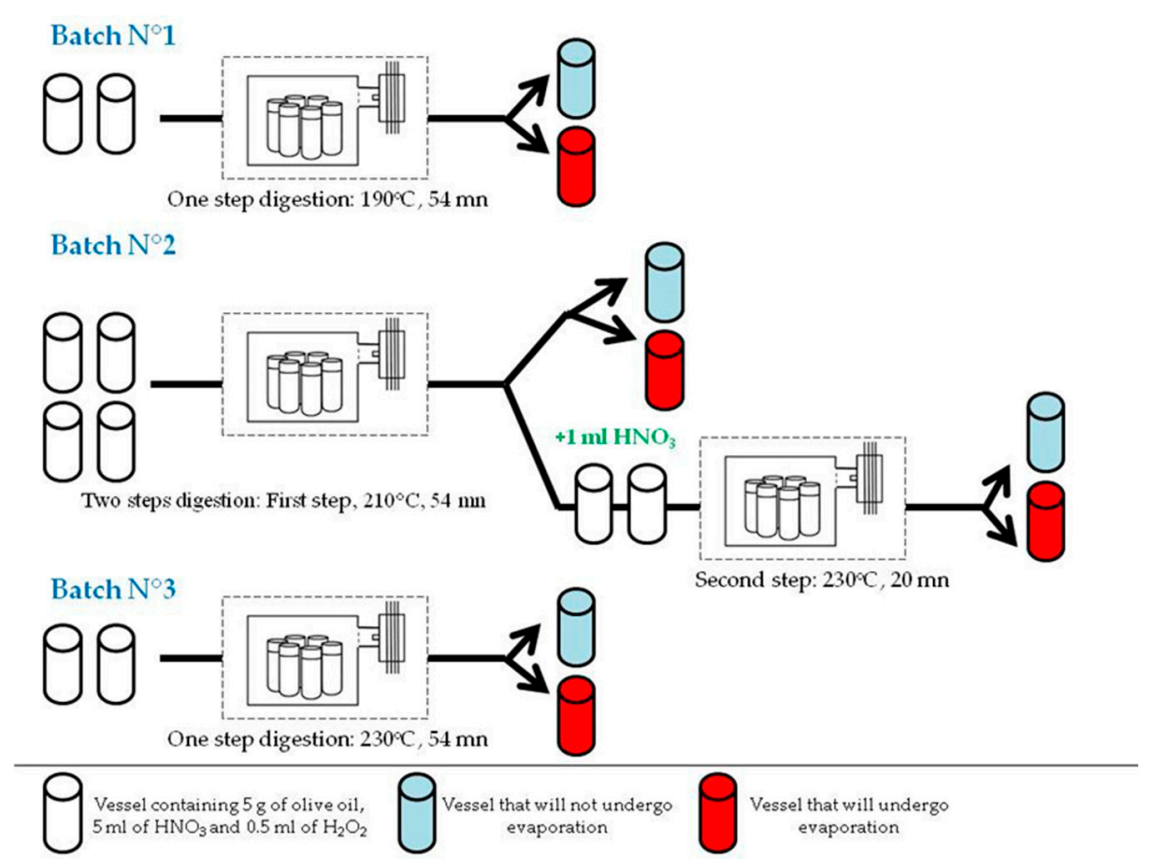

Figure 1. Scheme of optimization procedure for sample preparation prior to multielement determination by ICP-MS.

The microwave program was chosen according to the manufacturer's application note. The matrix that was the closest to that of olive oil was that of egg oil, so we have chosen the microwave program for egg oil digestion to digest samples of the first batch and then the temperature was increased by $20^{\circ} \mathrm{C}$ at two consecutive times in each step of the programs of the following two batches.

Following the digestion, the vessels that would not undergo evaporation were opened and their contents collected. The collected samples were then transferred to a DigiTUBE and their volume was adjusted to $25 \mathrm{~mL}$. Samples were then centrifuged and diluted two times prior to ICP-MS analysis.

Table 2 shows the microwave program used for digesting the oil samples in each of the three batches. Each digestion cycle was followed by a 5 min ventilation cycle.

Table 2. Operating program for the microwave system used for the three batches.

\begin{tabular}{ccccc}
\hline Batch $\mathbf{N}^{\circ}$ & Step & Time (mn) & Power (W) & Temp 1 ( $\left.{ }^{\circ} \mathbf{C}\right)$ \\
\hline & 1 & 2 & 1000 & 50 \\
2 & 3 & 31 & 0 & 30 \\
1 & 4 & 1 & 1000 & 190 \\
\cline { 2 - 5 } & 5 & 6 & 0 & 160 \\
& 6 & 13 & 1000 & 190 \\
& 1 & 2 & 1000 & 190 \\
\hline & 2 & 1 & 1000 & 70 \\
& 3 & 31 & 0 & 50 \\
& 4 & 1 & 1000 & 210 \\
& 5 & 13 & 0 & 180 \\
& 6 & 2 & 1000 & 210 \\
& 1 & 1 & 1000 & 90 \\
& 2 & 31 & 0 & 70 \\
& 3 & 1 & 1000 & 230 \\
& 4 & 6 & 0 & 200 \\
& 5 & 13 & 1000 & 230 \\
& 6 & & 1000 & 230 \\
\hline
\end{tabular}


The other vessels, that were to undergo evaporation, were opened and uncapped. The bomb body was then placed on a hotplate until the residual digest volume became approximately equal to $1 \mathrm{~mL}$ (it takes around $30 \mathrm{~min}$ to reach that volume). After that, $20 \mathrm{~mL}$ of $1 \% \mathrm{HNO}_{3}$ were gradually added to each vessel $(10 \mathrm{~mL}$ at the first step that were left to dissolve the residual digest for about $5 \mathrm{~min}$ and then the total volume transferred to DigiTUBE and additional $10 \mathrm{~mL}$ added to wash the vessel). The volume was finally brought to $25 \mathrm{~mL}$.

\section{Selection Criteria}

The quality of organic matrix decomposition was evaluated by determining the residual carbon content of the digested (RCCD) solutions. For the determination of RCCD, digested solutions were analyzed by ICP-MS using the semi-quantitative mode.

\subsubsection{Ultrasound-Assisted Extraction}

The samples were prepared according to the method of Camin et al. with minor modifications [16]. Briefly, $10 \mathrm{~g}$ of olive oil sample was weighed into a $50 \mathrm{~mL}$ conical bottom polypropylene centrifuge tube and $10 \mathrm{~mL}$ of the extracting aqueous solution was added. The extracting water solution was prepared with: $1 \% \mathrm{HNO}_{3}, 0.2 \% \mathrm{HCl}$ and $6.7 \% \mathrm{H}_{2} \mathrm{O}_{2}$. The mixture was then vortex-shaken for $30 \mathrm{~s}$ and placed in a an ultrasonic cleaning bath $\left(300 \mathrm{~W}, 26^{\circ} \mathrm{C}\right)$ with a capacity of $30 \mathrm{~L}$ for $15 \mathrm{~min}$ to extract the inorganic elements from the oil to the aqueous solution. The mixture was then centrifuged ( $3500 g \times 5 \mathrm{~min}$ ) into separate the two phases. The upper oil layer was carefully aspired and discarded, the lower aqueous phase collected, and $5 \mathrm{~mL}$ of it were poured into a $15 \mathrm{~mL}$ conical bottom polypropylene centrifuge tube and subjected to ICP-MS analysis.

\subsection{Quality Control for Performance Comparison}

Validation of an analytical method refers to the precise characterization of the procedure so the most valid, well founded, reliable and precise measurement results can be acquired with it. It is one of the most critical steps in the process of introducing a new method into practice. The method validation must be conducted using the evaluation of at least the basic performance criteria which include: The estimation of the accuracy, the limits of detection and quantification, and the precision of the method under repeatable conditions [19]. In this work, the microwave digestion and the ultrasound-assisted extraction methods are already well established and validated methods. Only the combined digestion-evaporation method needed to be validated in case it showed better performance than the other two methods. Therefore, the parameters presented below will serve to compare the performance of the three methods suggested in this work.

\subsubsection{Limit of Detection (LOD) and Limit of Quantification (LOQ)}

The values of LOD and LOQ are strongly related to measurement noise. LOD is the lowest concentration that can be measured (detected) by using a specified analytical procedure with statistical significance. LOQ is the lowest concentration that can be determined or quantified by using a specified analytical procedure with the established accuracy, precision and uncertainty.

LOD and LOQ of each element are calculated as three and ten times, respectively, for the standard deviation of the measurement of the specific element in ten independent method blank samples. Each method blank solution was prepared with the reagents used to prepare the samples and underwent the same analytical conditions as the samples [19].

\subsubsection{Precision (Relative Standard Deviation, RSD)}

It refers to the degree of variability among the independent measurements obtained by analysis of a specific sample by using a specific analytical method. Precision is usually expressed as a repeatability measurement of ten repeated determinations under the same conditions of a given 
sample on the same day, or it can be expressed as reproducibility measurement of ten different sample preparations on different days. In that case, it is expressed as a relative standard deviation [20]. For the microwave digestion method, precision assessment based on 10 independent samples was assessed herein by the mean RSDs of concentrations of the three replicates analyzed for each sample. The repeatability of the combined digestion-evaporation method was estimated based on seven independent replicates of a commercially available olive oil sample prepared and analyzed as described above. The repeatability of the ultrasound-assisted extraction was also calculated as a relative standard deviation of the concentrations of seven replicates of a commercial olive oil sample extracted and analyzed as explained above.

\subsubsection{Accuracy}

The accuracy means the nearness of test results to the true value. The most used and common procedure of accuracy determination is based on the independent measurements of ten replicates of a certified reference material (CRM) and it is reported as the percent recovery of the known certified value. Sometimes, CRMs are not easily available and this may complicate the validation of analytical methods. In this study, the determination of the accuracy was hindered by the absence in the market of certified reference vegetable or edible oil that can matrix match that of olive oil. Other authors have previously tried to measure the accuracy by spike and recovery, using aqueous standard solutions, peanut butter CRM, or synthetic standard oil $[6,16]$. In another study, the authors validated a method of ultrasound-assisted extraction of multielements from olive oils by using a pomace sample and calculating the relative recovery of the elements from the same pomace sample prepared by a microwave digestion [13]. But we believe that these methods are not the best because they do not represent the real matrix of the edible oil and are likely to show low recovery mainly due to the high viscosity of the certified reference or standard materials and difficulties to obtain homogeneous mixtures. It is therefore of primordial importance to push certifying bodies to develop edible and specifically vegetable oils CRMs to facilitate the complete and effective validation of the proposed analytical methods of inorganic elements' determination.

The accuracy of the microwave digestion method was checked in our previous study [12]. It was calculated by analyzing the multielement oil standard S23-100Y of $100 \mathrm{mg} \cdot \mathrm{kg}^{-1}$ concentration (SPEXCertiPrep, Metuchen, NJ, USA) three times after appropriate dilutions, and calculating the recovery. The accuracy of the ultrasound-assisted extraction was evaluated by spiking three replicates of a commercial olive oil sample with a multielement standard solution at the level of $100 \mu \mathrm{g} \cdot \mathrm{L}^{-1}$. The accuracy of the combined digestion-evaporation will not be determined, as this proposed method did not satisfy the primordial criteria of acceptable repeatability.

\subsection{ICP-MS Calibration}

Table 3 shows the calibration range of elements in olive oil samples in the three methods. External calibrations curves were built using a range of different mass concentrations prepared by a mixture of the following single-element and multi-element standard stock solutions: $10,000 \mathrm{mg} \cdot \mathrm{L}^{-1}$ Ca (SPEXCertiPrep, Metuchen, NJ, USA), $1000 \mathrm{mg} \cdot \mathrm{L}^{-1} \mathrm{Na}$ (SPEXCertiPrep, Metuchen, NJ, USA), $1000 \mathrm{mg} \cdot \mathrm{L}^{-1} \mathrm{Fe}$ (SPEXCertiPrep, Metuchen, NJ, USA), $1000 \mathrm{mg} \cdot \mathrm{L}^{-1} \mathrm{Mg}$ (SPEXCertiPrep, Metuchen, NJ, USA) and $10 \mathrm{mg} \cdot \mathrm{L}^{-1}$ XSTC-622B (SPEXCertiPrep, Metuchen, NJ, USA) (all in 5\% $\mathrm{HNO}_{3}$ ).

\section{Remark:}

(i) XSTC-622B contains the following elements: Li, B, Na, Mg, Al, Si, K, Ca, Ti, V, Cr, Fe, Mn, Co, $\mathrm{Ni}, \mathrm{Cu}, \mathrm{Zn}, \mathrm{Ga}, \mathrm{Ge}, \mathrm{As}$, Se, Rb, Sr, Zr, Mo, Ag, Cd, Sn, Sb, Cs, Ba, W and Pb. 
Table 3. Calibration range of elements in the three analytical methods' analysis by ICP-MS.

\begin{tabular}{ccccccc}
\hline & \multicolumn{6}{c}{ Solution Name (Concentrations in $\mu \mathrm{g} \cdot \mathbf{L}^{-1}$ ) } \\
\hline Method & $\mathbf{N a}$ & $\mathbf{C a}$ & $\mathbf{M g}$ & $\mathbf{F e}$ & XSTC-622B & $\mathbf{N}^{*}$ \\
\hline Digestion & - & - & - & - & $0.01-50$ & 8 \\
\hline $\begin{array}{c}\text { Combined } \\
\text { digestion-evaporation }\end{array}$ & $0.05-100$ & $0.025-50$ & $0.01-20$ & $0.01-20$ & $0.005-10$ & 11 \\
\hline Ultrasound-assisted extraction & $0.05-50$ & $0.025-25$ & $0.01-10$ & $0.01-10$ & $0.005-5$ & 12 \\
\hline
\end{tabular}

${ }^{*}$ number of calibration points evenly distributed across the corresponding range.

\section{Results and Discussion}

\subsection{Microwave-Assisted Digestion}

The Table 4 shows the results of performance criteria determinations for microwave-assisted digestion. The results shown are the ones collected during our previous study [12]. The linearity was very satisfactory with a linear regression coefficient greater than 0.999 for most of the elements. As for the LOD and LOQ, our results were significantly better than those reported in the original research [18] for the elements $\mathrm{Fe}, \mathrm{V}$ and As, and relatively similar for the element $\mathrm{Pb}$ (Table 5). As previously stated by Konieczka, the values of LOD and LOQ are strongly related to measurement noise [19]. Therefore, the improvement of these values for Fe, $\mathrm{V}$ and As could be due to a lower background levels of these elements achieved by using the reaction mode of the Elan DRC-e ICP-MS, which decreases the measurement noise. Indeed, an Agilent 7500a that is not equipped with a collision/reaction cell was used in the study conducted by Llorent-Martinez et al. [18]. The accuracy was in the range 84-102\% for almost all elements measured in the oil standard, except for $\mathrm{Mg}$ for which the accuracy was $66 \%$.

Table 4. Results of determination of analytical procedure parameters (Microwave digestion at $200{ }^{\circ} \mathrm{C}$, according to Llorent-Martinez et al., 2014 with minor modifications).

\begin{tabular}{|c|c|c|c|c|c|c|c|}
\hline Element & Isotope & $\begin{array}{c}\text { Operation } \\
\text { Mode }\end{array}$ & $\begin{array}{c}\text { LOD } \\
\left(\mu \mathrm{g} \cdot \mathrm{kg}^{-1)}\right.\end{array}$ & $\begin{array}{c}\mathrm{LOQ}(\mu \mathrm{g} \\
\left.\cdot \mathrm{kg}^{-1}\right)\end{array}$ & $\begin{array}{l}\text { Repeatability } \\
\text { (RSD \%) * }\end{array}$ & $\begin{array}{c}\text { Linearity } \\
\left(\mathbf{R}^{2}\right)\end{array}$ & $\begin{array}{c}\text { Accuracy } \\
(\%)\end{array}$ \\
\hline $\mathrm{Na}$ & 23 & Standard & 120 & 350 & 9.9 & 0.9998 & 84 \\
\hline $\mathrm{Mg}$ & 24 & Standard & 160 & 470 & 12 & 0.9991 & 66 \\
\hline $\mathrm{Fe}$ & 56 & $\operatorname{DRC}\left(\mathrm{CH}_{4}\right)$ & 120 & 390 & 13 & 0.9999 & 88 \\
\hline $\mathrm{Zn}$ & 66 & $\operatorname{DRC}\left(\mathrm{CH}_{4}\right)$ & 110 & 360 & 16 & 0.9997 & 97 \\
\hline $\mathrm{V}$ & 51 & Standard & 1.7 & 5.6 & 14 & 1.0000 & 97 \\
\hline $\mathrm{Mn}$ & 55 & Standard & 6.0 & 20 & 20 & 1.0000 & 103 \\
\hline As & 75 & Standard & 0.73 & 2.4 & 20 & 0.9990 & \\
\hline $\mathrm{Rb}$ & 85 & Standard & 0.30 & 1.0 & 17 & 0.9996 & \\
\hline $\mathrm{Sr}$ & 88 & Standard & 5.1 & 17 & 5 & 0.9999 & \\
\hline $\mathrm{Ba}$ & 138 & Standard & 4.6 & 15 & 15 & 1.0000 & 102 \\
\hline $\mathrm{Pb}$ & 208 & Standard & 6.9 & 23 & 21 & 1.0000 & 97 \\
\hline
\end{tabular}

* based on the mean RSD of three replicates of 21 olive oil samples.

Table 5. Comparison of the limits of detection of the microwave digestion method between our results and those of the original research (for elements in common).

\begin{tabular}{ccc}
\hline & \multicolumn{2}{c}{ LOD $\left(\mu \mathrm{g} \cdot \mathbf{K g}^{-\mathbf{1}}\right)$} \\
\hline Element & Our Study & Original Study \\
\hline $\mathrm{Fe}$ & 120 & 600 \\
$\mathrm{~V}$ & 1.7 & 15 \\
$\mathrm{As}$ & 0.73 & 15 \\
$\mathrm{~Pb}$ & 6.9 & 4 \\
\hline
\end{tabular}




\subsection{Combined Digestion-Evaporation}

\subsubsection{Carbon Content in Digest}

Sample digestion or decomposition is an important step in analytical methods for the routine determination of chemical elements in foodstuffs. The particular degree to which decomposition is complete was assessed by measuring the RCCD. The study with a one-step digestion at $190{ }^{\circ} \mathrm{C}$ followed by evaporation on a hotplate showed the lowest RCCD values compared to those obtained by higher temperatures or a two-step digestion process (Table 6). Overall, all the vessels that underwent evaporation after the microwave-digestion step showed lower residual carbon content. This result was expected as the prolonged exposure of the sample to heat over time in its acidic environment increases its decomposition rate and the release of the volatile carbon to the atmosphere. As for vessels that did not undergo evaporation, we noticed that the residual carbon content increased as the temperature increased, and it exceeded the range when a two-step digestion process was employed. This result can be attributed to one of these causes: We presume that the high temperatures and pressures inside the closed vessels would have caused recalcitrant organic compounds' formation to be difficult to decompose, leading to higher carbon content; or that the lower temperatures resulted in higher carbon content in reality but that caused lower sensitivities due to carbon deposition.

Table 6. Counts at mass number 12 corresponding to the most abundant isotopes of carbon: A comparative method of residual carbon content estimation under different decomposition conditions.

\begin{tabular}{ccccccccc}
\hline & \multicolumn{9}{c}{ One Step } & \multicolumn{2}{c}{ Two Steps } \\
\hline \multicolumn{3}{c}{$190^{\circ} \mathrm{C}$} & \multicolumn{2}{c}{$210{ }^{\circ} \mathrm{C}$} & & $230{ }^{\circ} \mathrm{C}$ & \multicolumn{2}{c}{$210^{\circ} \mathrm{C}$ then $230{ }^{\circ} \mathrm{C}$} \\
\hline Mass number & $\mathrm{NE}^{*}$ & $\mathrm{E}^{* *}$ & $\mathrm{NE}$ & $\mathrm{E}$ & $\mathrm{NE}$ & $\mathrm{E}$ & $\mathrm{NE}$ & $\mathrm{E}$ \\
\hline 12 & $172,855,743$ & $13,216,179$ & $217,036,881$ & $77,300,752$ & $219,254,250$ & $191,976,927$ & over range & $76,931,314$ \\
\hline \multicolumn{4}{c}{$\mathrm{NE}$, no evaporation; E, with evaporation. }
\end{tabular}

Efficient digestions should allow a complete decomposition of organic material, leading to low residual carbon contents [20]. The results presented in this study support the fact that digestion at $190^{\circ} \mathrm{C}$ followed by evaporation confirms the observations made by Castro et al. [21]. Consequently, we will determine the performance criteria of this method; namely: LOD, LOQ and precision as a first step of the method's development procedure.

\subsubsection{Performance Parameters of the Proposed Combined Digestion-Evaporation Method}

The table below (Table 7) shows the results of the performance criteria determination for the proposed method.

Linearity

The ICP-MS analysis was calibrated using eleven external standards, including the blank. Although ICP-MS is well known for a wide linear dynamic range, we checked the linear regression coefficient of the calibration curves. Linearity is considered satisfactory if the coefficient exceeds 0.999 [15]. $\mathrm{R}^{2}$ was greater than 0.999 for $\mathrm{Mg}, \mathrm{Ca}, \mathrm{V}, \mathrm{Cr}, \mathrm{Ni}, \mathrm{Zn}, \mathrm{As}, \mathrm{Rb}, \mathrm{Sr}, \mathrm{Mo}$ and Pb. The rest of the elements had lower coefficients, especially Fe which had the lowest one.

\section{LOD and LOQ}

When compared to the microwave digestion method, the combined digestion followed by evaporation method proposed here offers significantly better detection limits and consequently better quantification limits. 
Precision (Repeatability)

The results of repeatability obtained were not satisfactory and showed high spread around the mean. Elements such as $\mathrm{V}, \mathrm{Fe}, \mathrm{Rb}$ and Mo had RSDs higher than 30\%. V, Mn and As had RSDs higher than $50 \%$ (99\% for As). Since RSD estimation was based on counts and not on concentrations, the RSD is sometimes not representative of the real spread; for example, in the case of As, counts varied between 0 and nine, which means the As was almost absent from the sample solutions, so an RSD of $99 \%$ is not representative of the real situation in the case of low-count elements. But Fe had high counts $(n=7$ : $4274 \pm 1923)$ and still give an unsatisfactory RSD (45\%).

Table 7. Results of determination of analytical procedure parameters (Microwave digestion at $190{ }^{\circ} \mathrm{C}$ followed by evaporation).

\begin{tabular}{ccccccc}
\hline Element & Isotope & Mode & $\begin{array}{c}\text { LOD } \\
\left(\boldsymbol{\mu g} \cdot \mathbf{k g}^{-\mathbf{1}}\right)\end{array}$ & $\begin{array}{c}\text { LOQ } \mathbf{( \mu g} \cdot \\
\mathbf{k g} \mathbf{- 1})\end{array}$ & $\begin{array}{c}\text { Repeatability } \\
\left(\mathbf{R S D}_{\mathbf{\%})}\right.\end{array}$ & $\begin{array}{c}\text { Linearity } \\
\mathbf{( R}^{\mathbf{2}} \mathbf{)}\end{array}$ \\
\hline $\mathrm{Na}$ & 23 & $\mathrm{He}$ & 13 & 45 & 5.4 & 0.9985 \\
$\mathrm{Mg}$ & 24 & $\mathrm{He}$ & 3.5 & 11 & 27 & 0.9991 \\
$\mathrm{Ca}$ & 44 & $\mathrm{CH}_{4}$ & 190 & 640 & 6.6 & 0.9990 \\
$\mathrm{~V}$ & 51 & $\mathrm{He}$ & 0.012 & 0.041 & 53 & 0.9996 \\
$\mathrm{Cr}$ & 52 & $\mathrm{CH}_{4}$ & 0.47 & 1.6 & 25 & 0.9996 \\
$\mathrm{Mn}$ & 55 & $\mathrm{He}$ & 0.49 & 1.6 & 52 & 0.9989 \\
$\mathrm{Fe}$ & 56 & $\mathrm{He}$ & 5.8 & 19 & 45 & 0.9957 \\
$\mathrm{Ni}$ & 60 & $\mathrm{CH}_{4}$ & 2.5 & 8.2 & 26 & 0.9998 \\
$\mathrm{Cu}$ & 63 & $\mathrm{He}$ & 2.3 & 7.7 & 16 & 0.9989 \\
$\mathrm{Zn}$ & 64 & $\mathrm{CH}_{4}$ & 13 & 42 & 12 & 0.9997 \\
$\mathrm{As}$ & 75 & $\mathrm{He}$ & 0.093 & 0.31 & 99 & 0.9993 \\
$\mathrm{Rb}$ & 85 & $\mathrm{STD}$ & 0.036 & 0.12 & 38 & 1.000 \\
$\mathrm{Sr}$ & 88 & $\mathrm{STD}$ & 0.098 & 0.33 & 15 & 1.000 \\
$\mathrm{Mo}$ & 98 & $\mathrm{CH}$ & 0.15 & 0.51 & 46 & 0.9999 \\
$\mathrm{~Pb}$ & 208 & $\mathrm{STD}$ & 2.4 & 8.1 & 22 & 0.9999 \\
\hline
\end{tabular}

$\mathrm{He}$, Helium collision mode; $\mathrm{CH}_{4}, \mathrm{CH}_{4}$ dynamic reaction cell mode; $\mathrm{STD}$, no gas standard mode; $\mathrm{R}^{2}$, linear regression coefficient of calibration for LOD and LOQ determinations.

\subsection{Ultrasound-Assisted Extraction}

Table 8 shows the results of the performance criteria determination for the ultrasound-assisted extraction method.

Table 8. Results of determination of analytical procedure parameters for ultrasonic extraction of elements.

\begin{tabular}{|c|c|c|c|c|c|c|c|}
\hline Element & Isotope & Mode & $\begin{array}{c}\text { LOD } \\
\left(\mu \mathrm{g} \cdot \mathrm{kg}^{-1}\right)\end{array}$ & $\begin{array}{c}\mathrm{LOQ} \\
\left(\mu \mathrm{g} \cdot \mathrm{kg}^{-1}\right)\end{array}$ & $\begin{array}{c}\text { Repeatability } \\
\text { (RSD \%) }\end{array}$ & $\begin{array}{l}\text { Linearity } \\
\left(\mathbf{R}^{2}\right)\end{array}$ & $\begin{array}{c}\text { Accuracy } \\
(\%)\end{array}$ \\
\hline $\mathrm{Na}$ & 23 & $\mathrm{He}$ & 0.42 & 1.4 & 11 & 0.9985 & 136 \\
\hline $\mathrm{Mg}$ & 24 & $\mathrm{He}$ & 0.11 & 0.35 & 11 & 0.9986 & 73 \\
\hline $\mathrm{Ca}$ & 44 & $\mathrm{He}$ & 1.5 & 4.9 & 13 & 0.9811 & \\
\hline $\mathrm{Ti}$ & 47 & $\mathrm{He}$ & 0.16 & 0.45 & 11 & 0.9977 & \\
\hline V & 51 & $\mathrm{He}$ & 0.069 & 0.23 & 1.9 & 0.9975 & \\
\hline $\mathrm{Cr}$ & 52 & $\mathrm{He}$ & 0.035 & 0.12 & 12 & 0.9987 & 64 \\
\hline $\mathrm{Mn}$ & 55 & $\mathrm{He}$ & 0.0060 & 0.021 & 10 & 0.9979 & 67 \\
\hline $\mathrm{Fe}$ & 56 & $\mathrm{He}$ & 0.14 & 0.47 & 5.1 & 0.9984 & \\
\hline $\mathrm{Ni}$ & 60 & $\mathrm{CH}_{4}$ & 0.18 & 0.60 & 40 & 0.9974 & 81 \\
\hline $\mathrm{Cu}$ & 63 & $\mathrm{He}$ & 0.20 & 0.66 & 30 & 0.9931 & 80 \\
\hline $\mathrm{Zn}$ & 66 & $\mathrm{He}$ & 0.077 & 0.26 & 18 & 0.9988 & 84 \\
\hline As & 75 & $\mathrm{CH}_{4}$ & 0.036 & 0.12 & 6.2 & 0.9987 & \\
\hline $\mathrm{Rb}$ & 85 & STD & 0.00061 & 0.0021 & 8.9 & 0.9993 & 79 \\
\hline $\mathrm{Sr}$ & 88 & STD & 0.0025 & 0.0085 & 9.1 & 0.9993 & 77 \\
\hline Mo & 98 & STD & 0.0047 & 0.016 & 8.6 & 0.9970 & 78 \\
\hline $\mathrm{Ba}$ & 138 & STD & 0.0014 & 0.0049 & 13 & 0.9990 & 133 \\
\hline $\mathrm{Pb}$ & 208 & STD & 0.0035 & 0.012 & 13 & 0.9989 & \\
\hline
\end{tabular}

$\mathrm{He}$, Helium collision mode; $\mathrm{CH}_{4}, \mathrm{CH}_{4}$ dynamic reaction cell mode; $\mathrm{STD}$, no gas standard mode; $\mathrm{R}^{2}$, linear regression coefficient of calibration for LOD and LOQ determinations. 


\subsubsection{Range of Linearity}

The ICP-MS analysis was calibrated using twelve external standards, including the blank. Although ICP-MS is well known for a wide linear dynamic range, we checked the linear regression coefficient of the calibration curves. $R^{2}$ obtained for most of the elements was satisfactory with some exceptions. $\mathrm{Cu}$ had the lowest coefficient (0.9931) and only the alkaline $\mathrm{Rb}$, Sr and Ba had coefficients equal or higher than 0.999 .

\subsection{2. $\mathrm{LOD}$ and LOQ}

When compared to the microwave digestion method, the ultrasound-assisted extraction method offers significantly better detection limits and consequently better quantification limits. The sensitivity improvement varied from eight-fold for $\mathrm{Rb}$ to as high as 20,000 fold for Fe. The obtained LOD values were in the same range of those reported in previous studies on ultrasound-assisted extraction of elements from olive oils $[13,16]$.

\subsubsection{Precision (Repeatability)}

The results of repeatability obtained for the sonication method were very satisfactory compared to the two previous methods. Fourteen elements had RSDs lower than $13.4 \%$ whereas $\mathrm{Ni}, \mathrm{Cu}$ and $\mathrm{Zn}$ had the least satisfactory RSDs (40\%, 30\% and 18\% respectively) but that is still the best compared to the other methods.

\subsubsection{Accuracy}

The accuracy was in the range $63 \%-136 \%$ for the determined elements measured in the spiked oil samples, which were more scattered than the accuracy results of the microwave digestion method. Overall, the ultrasound-assisted extraction sowed less recovery than the microwave digestion for most of the elements, as expected except for $\mathrm{Na}$ and $\mathrm{Ba}$, but the results were generally deemed satisfying [17].

\subsection{Comparison between the Three Methods}

Based on the results presented above, the combined digestion-evaporation and the ultrasound-assisted extraction performed better than the microwave digestion as judged by the detection limits. So it is advantageous to replace the microwave digestion only by one of these two proposed methods to improve the detection limits and widen the range of the mass numbers that can be detected by the ICP-MS in the olive oil samples. Our results agree with those recently reported by Pošćic et al., stating that the microwave acid digestion does not allow measurement of elements present at very low concentrations even if the ICP-MS technique is used for detection [13]. This is because of the limited amount of sample that can be processed. The high pressure that develops during digestion owing to the high organic matter and high fatty acid content of the olive oil restrains the amount of sample allowed into the digestion vessel. Moreover, the residual acidity in the digests make it mandatory to dilute samples prior to ICP-MS analysis, which lowers the concentration of the elements, and may make them within the same range of the blank for some elements that are initially present at trace levels, and therefore make them undistinguishable from the uncertainty of the blank (i.e., very close or below the detection limit). Moreover, the same authors reported high detection limits obtained by the microwave digestion only, as they could detect only seven $(\mathrm{Cu}, \mathrm{K}, \mathrm{Mg}, \mathrm{Mn}, \mathrm{P}, \mathrm{Rb}$ and $\mathrm{S})$ out of the twenty-nine measured elements [13]. In another study comparing the performance of microwave digestion and simple dilution of wine samples prior to ICP-MS measurement, the authors reported that the detection limits for most elements in the digested samples were between two and 10 times higher than those for the diluted samples, and attributed these findings to the higher background in the method blanks of the digested samples. That higher background was due to the impurities in the reagents used to mineralize the samples and to possible contamination from the digestion vessels [22]. 
When compared together, the ultrasound-assisted extraction performed better than the combined microwave digestion-evaporation method, as judged by the detection limit and the precision expressed as repeatability. Those lower detection limits and the higher precision can be explained by the fact that the ultrasound-assisted extraction method uses fewer steps to extract the elements from the samples and to prepare the method blanks. On top of that, this preparation method exposes the samples to the laboratory environment for a shorter duration of time which means that it reduces the contamination risk. In fact, the dependable determination of elements at very low levels in organic materials is significantly determined by the ability to control and reduce contamination in the method blanks and sample solutions during sample preparation, because detection limits' estimation is based on the variability of the blanks. This confirms the statement that an effective sample preparation method is the one that involves minimal preparation steps, since the risks of loss or contamination are then limited [20]. It remains important to say that to determine the accuracy of the preparation methods easily and efficiently, the use of vegetable oil CRM is recommended. This task is hindered at the moment by the absence of matrix matching CRMs. For this reason, it is extremely urgent to conduct future research to develop vegetable oil CRMs. This is crucial to help truly validate existent and future multielement determination methods, taking into account that, until now, most of the validations are based on spiking natural oils with natural or synthetic oils or butters, and recovery of the elements or calculations of the relative recovery, by comparison with another established method. It is worth noting that it is very challenging to obtain homogenous and representative samples with the currently available ultra-viscous oil or butter standards to reflect the reality of the vegetable oil matrices.

\section{Conclusions}

The accurate determination of multielements in olive oils is often limited by contamination encountered during sample preparation rather than sensitivity of the analytical technique. We believe that the ultrasound-assisted extraction of multielements from olive oil samples is preferred over the most commonly used microwave-assisted digestion procedure, because of the following advantages: Lower detection limits, higher precision, less risk of contamination due to exposure to the laboratory surrounding environment, less time-consuming and simple sample preparation. Future research work should focus on developing edible oils' CRMs, to aid in the validation of proposed analytical methods for high outcome-confidence, given the implication and importance of multielements in authentication, traceability and quality issues.

Author Contributions: Conceptualization, F.D. and M.A.; methodology, F.D.; validation, F.D. and K.B.; investigation, F.D. and K.B.; resources, K.B. and K.T.; data curation, F.D; writing-original draft preparation, F.D.; writing - reviewing and editing, all authors; supervision, M.K. and K.T.; project administration, F.D.; funding acquisition, K.T.

Funding: This research was financially supported by the JICA-JST joint Science and Technology Research Partnership for Sustainable Development (SATREPS) Project, "Valorization of Bioresources in Semi-Arid and Arid Land for Creation of New Industry," grant number: JPMJSA1506.

Acknowledgments: The authors would like to thank Aomi Suda for providing the laboratory hotplate to perform the evaporation experiment.

Conflicts of Interest: The authors declare no conflict of interest. The funders had no role in the design of the study; in the collection, analyses, or interpretation of data; in the writing of the manuscript; or in the decision to publish the results.

\section{References}

1. Kelly, S.; Heaton, K.; Hoogewerff, J. Tracing the geographical origin of food: The application of multi-element and multi-isotope analysis. Trends Food Sci. Technol. 2005, 16, 555-567. [CrossRef]

2. Szyczewski, P.; Frankowski, M.; Zioła-Frankowska, A.; Siepak, J.; Szyczewski, T.; Piotrowski, P. A comparative study of the content of heavy metals in oils: Linseed oil, rapeseed oil and soybean oil in technological production processes. Arch. Environ. Prot. 2016, 42, 37-40. [CrossRef] 
3. Dammak, I.; Neves, M.; Souilem, S.; Isoda, H.; Sayadi, S.; Nakajima, M. Material Balance of Olive Components in Virgin Olive Oil Extraction Processing. Food Sci. Technol. Res. 2015, 21, 193-205. [CrossRef]

4. Lepri, F.G.; Chaves, E.S.; Vieira, M.A.; Ribeiro, A.S.; Curtius, A.J.; DeOliveira, L.C.C.; Decampos, R.C. Determination of Trace Elements in Vegetable Oils and Biodiesel by Atomic Spectrometric Techniques-A Review. Appl. Spectrosc. Rev. 2011, 46, 175-206. [CrossRef]

5. Zeiner, M.; Steffan, I.; Cindrić, I.J. Determination of trace elements in olive oil by ICP-AES and ETA-AAS: A pilot study on the geographical characterization. Microchem. J. 2005, 81, 171-176. [CrossRef]

6. Benincasa, C.; Lewis, J.; Perri, E.; Sindona, G.; Tagarelli, A. Determination of trace element in Italian virgin olive oils and their characterization according to geographical origin by statistical analysis. Anal. Chim. Acta 2007, 585, 366-370. [CrossRef] [PubMed]

7. Cindrić, I.J.; Zeiner, M.; Steffan, I. Trace elemental characterization of edible oils by ICP-AES and GFAAS. Microchem. J. 2007, 85, 136-139. [CrossRef]

8. Mendil, D.; Dogan Uluözlüa, O.; Tüzena, M.; Soylak, M. Investigation of the levels of some element in edible oil samples produced in Turkey by atomic absorption spectrometry. J. Hazard. Mater. 2009, 165, 724-728. [CrossRef]

9. Gonzálvez, A.; Ghanjaoui, M.; El Rhazi, M.; De La Guardia, M. Inductively Coupled Plasma Optical Emission Spectroscopy Determination of Trace Element Composition of Argan Oil. Food Sci. Technol. Int. 2010, 16, 65-71. [CrossRef]

10. Llorent-Martínez, E.J.; Ortega-Barrales, P.; Córdova, M.F.-D.; Dominguez-Vidal, A.; Ruiz-Medina, A.; Pilar, O.-B. Investigation by ICP-MS of trace element levels in vegetable edible oils produced in Spain. Food Chem. 2011, 127, 1257-1262. [CrossRef]

11. Ni, Z.; Chen, Z.; Yu, Q.; Sun, X.; Tang, F. Microwave-assisted digestion for trace elements analysis of tree nut oil: Evaluation of residual carbon content. Spectrosc. Lett. 2019, 51, 1-6. [CrossRef]

12. Damak, F.; Asano, M.; Baba, K.; Suda, A.; Araoka, D.; Wali, A.; Isoda, H.; Nakajima, M.; Ksibi, M.; Tamura, K. Interregional traceability of Tunisian olive oils to the provenance soil by multielemental fingerprinting and chemometrics. Food Chem. 2019, 283, 656-664. [CrossRef] [PubMed]

13. Pošćić, F.; Turk, M.F.; Bačić, N.; Mikac, N.; Bertoldi, D.; Camin, F.; Špika, M.J.; Žanetić, M.; Rengel, Z.; Perica, Z. Removal of pomace residues is critical in quantification of element concentrations in extra virgin olive oil. J. Food. Compos. Anal. 2019, 77, 39-46. [CrossRef]

14. Bressy, F.C.; Brito, G.B.; Barbosa, I.S.; Teixeira, L.S.G.; Korn, M.G.A. Determination of trace element concentrations in tomato samples at different stages of maturation by ICP OES and ICP-MS following microwave-assisted digestion. Microchem. J. 2013, 109, 145-149. [CrossRef]

15. Chudzinska, M.; Debska, A.; Baralkiewicz, D. Method validation for determination of 13 elements in honey samples by ICP-MS. Accredit. Qual. Assur. 2012, 17, 65-73. [CrossRef]

16. Camin, F.; Larcher, R.; Perini, M.; Bontempo, L.; Bertoldi, D.; Gagliano, G.; Nicolini, G.; Versini, G. Characterisation of authentic Italian extra-virgin olive oils by stable isotope ratios of $\mathrm{C}, \mathrm{O}$ and $\mathrm{H}$ and mineral composition. Food Chem. 2010, 118, 901-909. [CrossRef]

17. Trindade, A.S.; Dantas, A.F.; Lima, D.C.; Ferreira, S.L.; Teixeira, L.S. Multivariate optimization of ultrasound-assisted extraction for determination of $\mathrm{Cu}, \mathrm{Fe}, \mathrm{Ni}$ and $\mathrm{Zn}$ in vegetable oils by high-resolution continuum source atomic absorption spectrometry. Food Chem. 2015, 185, 145-150. [CrossRef] [PubMed]

18. Llorent-Martínez, E.J.; Córdova, M.L.F.-D.; Ortega-Barrales, P.; Ruiz-Medina, A. Quantitation of Metals During the Extraction of Virgin Olive Oil from Olives Using ICP-MS after Microwave-assisted Acid Digestion. J. Am. Oil Chem. Soc. 2014, 91, 1823-1830. [CrossRef]

19. Konieczka, P. The Role of and the Place of Method Validation in the Quality Assurance and Quality Control (QA/QC) System. Crit. Rev. Anal. Chem. 2007, 37, 173-190. [CrossRef]

20. Khan, N.; Jeong, I.S.; Hwang, I.M.; Kim, J.S.; Choi, S.H.; Nho, E.Y.; Choi, J.Y.; Kwak, B.-M.; Ahn, J.-H.; Yoon, T.; et al. Method validation for simultaneous determination of chromium, molybdenum and selenium in infant formulas by ICP-OES and ICP-MS. Food Chem. 2013, 141, 3566-3570. [CrossRef] 
21. Castro, J.T.; Santos, E.C.; Santos, W.P.; Costa, L.M.; Korn, M.; Nóbrega, J.A.; Korn, M.G.A. A critical evaluation of digestion procedures for coffee samples using diluted nitric acid in closed vessels for inductively coupled plasma optical emission spectrometry. Talanta 2009, 78, 1378-1382. [CrossRef]

22. Coetzee, P.P.; Steffens, F.E.; Eiselen, R.J.; Augustyn, O.P.; Balcaen, L.; Vanhaecke, F. Multi-element Analysis of South African Wines by ICP-MS and Their Classification According to Geographical Origin. J. Agric. Food Chem. 2005, 53, 5060-5066. [CrossRef]



(C) 2019 by the authors. Licensee MDPI, Basel, Switzerland. This article is an open access article distributed under the terms and conditions of the Creative Commons Attribution (CC BY) license (http://creativecommons.org/licenses/by/4.0/). 